\title{
Analyzing Drivers' Intention to Accept Parking App by Structural Equation Model
}

\author{
Chang Yang $\mathbb{D},{ }^{1}$ Xiaofei Ye $\mathbb{D},{ }^{2}$ Jin Xie, ${ }^{1}$ Xingchen Yan $\mathbb{D}^{\circ},{ }^{3}$ Lili Lu $\mathbb{D},{ }^{4}$ Zhen Yang $\mathbb{D},^{3}$ \\ Tao Wang, ${ }^{5}$ and Jun Chen $\mathbb{1 D}^{6}$ \\ ${ }^{1}$ Faculty of Maritime and Transportation, Ningbo University, Fenghua Road 818\#, Ningbo 315211, China \\ ${ }^{2}$ Ningbo Port Trade Cooperation and Development Collaborative Innovation Center, \\ Faculty of Maritime and Transportation of Ningbo University, Fenghua Road 818\#, Ningbo 315211, China \\ ${ }^{3}$ College of Automobile and Traffic Engineering, Nanjing Forestry University, Longpan Road 159\#, Nanjing 210037, China \\ ${ }^{4}$ National Traffic Management Engineering \& Technology Research Centre Ningbo University Sub-Center, \\ Faculty of Maritime and Transportation of Ningbo University, Fenghua Road 818\#, Ningbo 315211, China \\ ${ }^{5}$ School of Architecture and Transportation, Guilin University of Electronic Technology, Lingjinji Road 1\#, Guilin 541004, China \\ ${ }^{6}$ School of Transportation, Southeast University, Si Pai Lou 2\#, Nanjing 210096, China
}

Correspondence should be addressed to Xiaofei Ye; yexiaofei@nbu.edu.cn

Received 28 October 2019; Revised 19 January 2020; Accepted 10 February 2020; Published 22 April 2020

Academic Editor: Gonçalo Homem de Almeida Correia

Copyright (c) 2020 Chang Yang et al. This is an open access article distributed under the Creative Commons Attribution License, which permits unrestricted use, distribution, and reproduction in any medium, provided the original work is properly cited.

With the concept of sharing economic entering into our lives, many parking Apps are designed for connecting the drivers and vacated parking spaces. However, there are not many drivers who use the mobile Apps to reserve and find available parking spaces, which is largely due to the insufficient information provided by the parking App. In order to better explain, predict, and improve drivers' acceptance of parking App, the conceptual framework based on technology acceptance model was developed to establish the relationships between the drivers' intention to accept parking App, trust in parking App, perceived usefulness of parking App, and perceived ease of its use. Then structural equation model was established to analyze the relationship between various variables. The results show that the trust in parking App, perceived usefulness, perceived ease of use, and parking App attributes are the main factors that determine the intention to use parking App. Through the test of direct effect, indirect effect, and total effect in the model, it is found that perceived usefulness has the largest total impact on acceptance intention, with a standardized coefficient of 0.984, followed by parking App attribute (0.743), perceived ease of use (0.384), and trust in parking App (0.381).

\section{Introduction}

With the sustained rapid growth of car ownership, parking has become difficult to issue a common phenomenon in large and medium cities. Shared parking mode has been applied to solve the problem of "parking difficulty." It becomes a hot topic in the parking industry and academic research. As the development of sharing economy in the transportation field, Mobile Apps of smart parking are designed to use the connectivity of the mobile Internet to share the use of personal parking berth after "online carhailing" and "shared bicycle." More than 100 Apps are launched in market and provide different functions. Both the
Mobile Apps and websites feature a scrollable listing of every parking facility and its parking space availability, price, address, and other information. The Apps and websites also allow drivers to reserve the parking space, permit the owner to share parking space, and admit manager to allocate and assign the optimal parking spaces to drivers automatically. Unlike Didi and Uber ride-hailing and shared bike Apps, shared parking App has not been accepted by the drivers, owners, and other users. Actually, the parking App provides the information that connects the driver and the vacant parking space. If the drivers do not use the parking information from the App, they would be cruising for parking and the App could not bring convenience to the driver and 
improve the parking difficulty. Therefore, it is of great value to better understand why the driver accepts or rejects the parking App. The overall objective of this study is to analyze the parking App acceptance of the drivers from their intentions and explain their intentions in terms of trust in parking App, perceived usefulness, perceived ease of use, and other related variables. A conceptual framework based on the technology acceptance model is proposed to establish the relationship between driver's intention to apply parking App and trust in parking App, perceived usefulness, perceived ease of use, and other related variables. Then the structural equation model (SEM) is applied to analyze the relationship among these variables. The research problems are addressed as follows.

(i) What are the significant relationships among drivers' intention to accept parking App, trust in parking App, perceived usefulness, perceived ease of use, and other related variables?

(ii) How to put forward the strategy of promoting parking App and understand the user behavior mechanism based on SEM results?

\section{Literature Review}

Many scholars have studied the influence of travel information on travel behavior. Chorus et al. [1,2] found that even if the traffic information was useful, its influence on driver's travel mode selection was tiny. Dziekan and Kottenhoff [3] found the real-time public transport information had a significant effect on the passengers' waiting time perception, with a survey showing that perception of waiting time could be reduced by $20 \%$ in the streetcar. Brakewood et al. [4] studied the real-time information in improving the uncertainty of bus operation and the perception, behavior, and satisfaction of passengers. They found that the application of bus information could significantly improve the travel satisfaction of passengers and reduce the perceived waiting time of passengers, as well as their anxiety and tension.

In terms of travel information demand, use, and acceptance, Goulias et al. [5] studied the use of advanced travel information system by passengers and found that four main media-TV, Internet, radio, telephone, and mobile communication technologies-all had impacts on passengers' use awareness, and the influence would change over household and personal characteristics. Molin and Timmermans [6] found that the willingness of passengers to pay for public transport information could be increased by improving the quality of information and providing additional information services such as travel planning. Grotenhuis et al. [7] studied the quality of passengers' demand for multimode travel information and found that passengers had a strong demand for travel information to reduce time (travel and search time) and save energy (physical, cognitive, and affective energy). Farag and Lyons [8] found the use awareness, habits, attitudes, anticipated emotions, and perceived behavior control would have a significant impact on the use of public transport information. Farag and Lyons
[9] found sociodemographics, travel information, social environment, and travel attitude have strong influences on the use of public transport information. It is suggested that public transport information could be provided with public transport use to fully release the service potential of public transport information.

As for the study on travelers' use of taxi-hailing App, Liu [10] found the practicability of App was the main factor influencing the acceptance of taxi-hailing App by Shanghai passengers, and the convenience of use had a certain influence on the practicability. Peng et al. [11] analyzed the use of calltaxi App by behavioral intention and found that perceived ease of use, perceived usefulness, and compatibility positively and indirectly affect use attitude and then affect use intention, while subjective norms positively and directly affect the behavior intention and perceived risk negatively and directly affect the behavior intention, and perceived price level has an impact on both the behavior intention and the use attitude, base of which were the theory of planned behavior (TPB), the theory of rational behavior (TRA), and the technology acceptance model (TAM). Zhang et al. [12] established Binary Logit Model to describe the tendency of travel mode selection, and the sensitivity of different influencing factors to the selection probability was discussed through sensitivity analysis, which provided reference for the development of traditional taxi and taxi-hailing App.

In terms of the design of parking App, there is little study. Tang [13] proposed internal guidance scheme in parking lots, through applying Dijkstra algorithm to the path guidance in parking lots. Song [14] designed the parking App system database, and the overall design provided overall technical support for the later implementation and development of the mobile parking App system. Based on the combination of Internet and mobile Internet, the designed parking App solved the insufficiency of traditional Apps.

Many scholars have studied the impact of travel App on travelers' behavior. Hancer and Jin [15] explored the influencing factors of travelers' attitude towards using travel Apps combined the theory of motivation, and found that App use experience had a moderating effect on influencing factors. Kwon et al. [16] used technology acceptance behavior model to study travelers' downloading behavior of travel App. Shaila et al. [17] identified that age and attitudes (toward smartphone use and environment) played a significant role in using smartphones for trip planning as well as shaping travel outcomes through binary choice modeling approach. Millennials (16-34 years) were more likely to use smartphones for trip planning and perceived increase in travel outcomes compared to other age groups. Xie et al. [18] proposed a modeling framework which was essential for accounting the impacts of real-time on-demand system's dynamics on traveler behaviors and capturing consumer heterogeneity, thus being greatly relevant for integrations in multimodal dynamic simulators.

\section{Conceptual Framework}

The technology acceptance model (TAM) is derived from Theory of Reasoned Action (TRA) of Fishbein and Ajzen 
[19]. TAM's central argument is that perceived usefulness and perceived ease of use are the determinants of behavioral intention prior to the adoption of a new technology, in which the intention is the antecedent of actual use [20]. TAM has been applied more and more in the field of transportation research in recent years. For example, TAM was developed to study the user acceptance of autonomous vehicle [21]. Parking App applies information technology to provide parking reservation and allocation services; therefore, TAM could also be applied to study driver's intention to accept the parking service provided by the parking App.

\subsection{Technology Acceptance Model. According to TAM, a} person's acceptance of a specified technology is determined by his or her behavioral intentions regarding the technology, which can be determined by his or her attitude toward the technology. TAM includes two particular factors, perceived usefulness and perceived ease of use [22], to explain the user's intentions and attitude toward technology shown in Figure 1. Perceived usefulness is the degree to which an individual believes that using a specific technology will help him or her to attain gains in job performance. Perceived ease of use refers to the degree of ease associated with use of the specific technology.

Specifically, the perceived usefulness is significantly related to the user's intention to accept parking App, and perceived ease of use significantly influences the user's acceptance intentions as well as the user's perceived usefulness. Likewise, the more useful and easier to use the drivers believe that the parking App is, the more the drivers would accept the App. Therefore, the following hypothesises are proposed.

3.1.1. Perceived Usefulness. The extent to which users think that using a technology or a system can help their work performance is affected by external variables. When users think the system is easy to use, they will complete more work with the same effort and improve work performance. Therefore, the following hypothesis is put forward.

Hypothesis $1\left(H_{1}\right)$. Drivers' perceived usefulness significantly and positively relates to their intention to accept parking App.

3.1.2. Perceived Ease of Use. The degree to which users perceive that technology is easy to use is affected by external variables (such as user characteristics, system characteristics, and organizational factors). The easier the system is to use, the stronger the user's sense of control and confidence will be, and their attitude towards the system will be more positive. Therefore, the following hypotheses are put forward.

Hypothesis $2\left(\mathrm{H}_{2}\right)$. Drivers' perceived ease of use significantly and positively relates to their perceived usefulness.
Hypothesis $3\left(\mathrm{H}_{3}\right)$. Drivers' perceived ease of use significantly and positively relates to users' intention to accept parking App.

By then, TAM is going two steps further. The attitude and behavioral intention to use parking App are discussed as follows.

3.1.3. Attitude to Use. Drivers' positive or negative feelings towards the use of information technology are influenced by perceived usefulness and perceived ease of use. When drivers feel that the parking App is more useful and convenient to use, they will have a more positive attitude towards the App.

3.1.4. Behavioral Intention. The subjective possibility of drivers' repeated use of parking App is influenced by personal attitude and perceived usefulness and directly determines their actual use behavior.

\subsection{Extension of TAM for Drivers' Intention to Accept Parking} App. Since TAM ignores some important factors like social influence in some specified situations, Venkatesh and Davis [23] proposed TAM2 by introducing social influence variables (including subjective norm and image) and the cognitive instrumental variables (work correlation, the quality of output, and the results demonstration) to explain the perceived usefulness and intention to use TAM2 repairs the empirical shortage problem of TAM, and enhances the adaptability of TAM.

Similarly, the current study extends TAM by introducing three new factors-parking App attributes, trust in parking App, and sociodemographics-according to the characteristics of parking App in this study. On the basis of the following analysis, the structural model for drivers' intention to accept parking App is developed (Figure 2).

3.2.1. Parking App Attributes. Parking App provides the service that links parking users with available parking spaces. Therefore, the information provided by parking App becomes one of the decisive factors for drivers to accept this information and use this App to park. The adequacy and accuracy of the information provided by the parking App is crucial, such that whether the functions of parking reservation, tracking parked vehicle inside parking area, parking assignment, and electronic payment are open, as well as whether the fluctuation of parking charge and the quantity of available parking spaces are accurate. Numerous early studies $[24,25]$ of travel information have confirmed that the reliability and timeliness of such information can influence travelers' acceptance of it. The following hypothesis is proposed for parking App attributes in this study.

Hypothesis $4\left(H_{4}\right)$. Parking App attributes significantly and positively relates to drivers' intention to accept parking App.

3.2.2. Trust in Parking App. The author gives the definition of trust in parking App, that is, the degree to which the traffic 


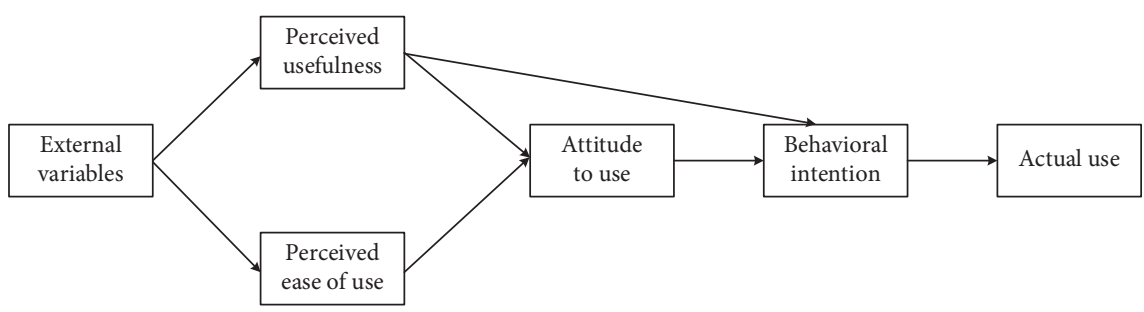

FIgURE 1: Technology acceptance model (TAM).

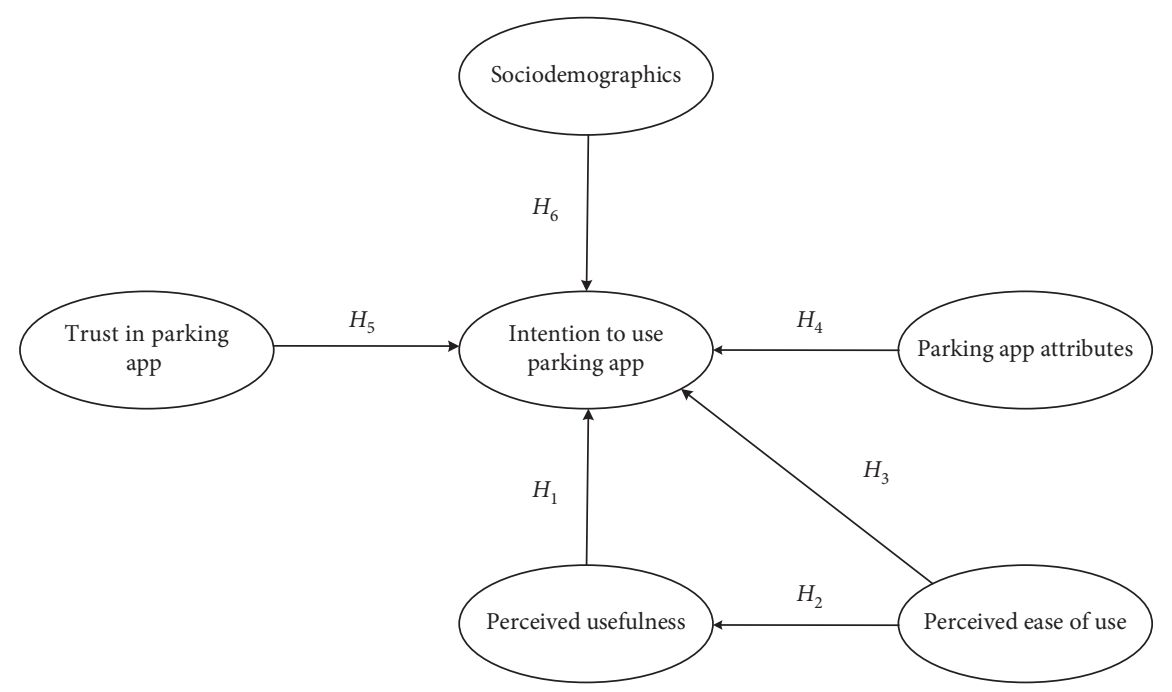

FIgURE 2: Structural model of drivers' intention to accept parking App.

information service provided by parking App can be trusted by specific users. Therefore, in a smart parking system with uncertainty, it is significantly necessary to analyze the credibility of parking App and identify the risks it may bring, so as to effectively develop a credible parking App. As a new product, parking App inevitably has the problem of trust. On one hand, the trust is not enough to support the operation of parking App. On the other hand, due to the public's ambivalence towards emerging things, users would like to try it but also be afraid of failure at the same time. If the parking App as an object cannot meet the needs of the users, then users' trust in the parking App will be greatly reduced. For example, inaccurate and uncertain parking location and prices might cause the driver to spend more time and money on parking. As a result, drivers will gradually abandon using parking App because of distrust caused by its inaccuracy. Users' trust in the parking App is mainly reflected in their trust in the parking information provided by the App. Therefore, the following hypothesis is proposed.

Hypothesis $5\left(\mathrm{H}_{5}\right)$. Trust in parking App significantly and positively relates to drivers' intention to accept parking App.

3.2.3. Sociodemographics. Gender, age, driving age, occupation, education, and local working hours of drivers could have a certain impact on their intention to use parking App [26]. For example, because of familiarity with local parking facility, older drivers with rich parking experience tend to park using their own judgement instead of parking App. So the following hypothesis is given.

Hypothesis $6\left(H_{6}\right)$. Sociodemographics of drivers significantly and positively relate to drivers' intention to accept parking App.

\section{Data and Variables}

4.1. Questionnaire and Variables. Since trust in parking App, perceived usefulness, and other latent variables cannot be measured directly in the structural model just mentioned, proper multiple observed indicator variables must be used to define them. In order to guarantee that the observed indicator variables are reasonable, they are selected on the basis of the conceptual framework just mentioned, according to existing literature about smart parking system. Observed indicator variables for each latent variable are detailed in Table 1.

In the questionnaire, except for the six questions of sociodemographics (SD1-6), the remaining questions were all graded by Likert scale with five points: strongly agree, relatively agree, generally agree, relatively disagree, and strongly disagree, which were graded on a scale of 5 to 1 .

4.2. Sample. Like other cities in China, the centripetal nature of Ningbo's urban construction and development has led to 
TABLE 1: Variable used in model.

\begin{tabular}{lc}
\hline Latent variable & Observed indicator variable \\
\hline & SD1: gender \\
SD2: age \\
Sociodemographics & SD3: driving years \\
& SD4: how long have you worked in this city? \\
SD5: occupation \\
SD6: education
\end{tabular}

PAA1: parking App provides accurate information of parking charges.

PAA2: parking App provides accurate information of the number of available parking spaces.

PAA3: parking App needs to open parking reservation function.

Parking App attributes $\quad$ PAA4: parking App needs to open the function of internal guidance and parked vehicles track inside parking area.

PAA5: parking App needs to open electronic payment function.

PAA6: the update speed of parking information by parking App is fast and timely.

PU1: it helps to check the parking App when looking for available parking space.

Perceived usefulness PU2: always checking the parking information by parking App while looking for available parking space.

Trust in parking App

TPA1: the parking information by parking App is insignificant.

TPA2: I have more trust in my own parking experience than parking App.

Perceived ease of use

PEOU1: when looking for available parking lot, checking the parking App can be a hassle. PEOU2: checking the parking App will take more time and cause inconvenience.

Intention to use parking App

IUPA1: be willing to use parking App when looking for available parking space.

the formation of high-density land use in the urban center, which has resulted in high-intensity transportation. Neither the road conditions nor the building parking standards can meet the traffic mode dominated by cars. Therefore, it is necessary to study Ningbo people's acceptance intention of parking App. Through the Internet and field survey, data collection of shared parking intention was carried out. The field survey was conducted in the Gulou, Chenghuang temple, Yuehu shengyuan, and Yinzhou district of Ningbo city for four days. The survey focused on public parking that charge fees, including in-road and off-road public parking; that is because in China, fee parking lot is the majority. Finally, 450 questionnaires were sent out. To maintain the accuracy of the estimations and proper solutions, ensure representativeness, and use multiple observed indicator variables to define latent variables, a much larger and sufficient sample size, from 100 to 200 , is recommended when maximum likelihood estimation is used [27]. According to the study, a sample size of 450 is adequate for SEM.

Among the 450 valid questionnaires, for the parking suppliers, $57 \%$ of respondents were male and $43 \%$ were female. There is nearly the same number of males and females, which makes it reasonable to analyze the intention to use parking App. As to the mean of different demographic characteristics in the sample, the average age of drivers is 37.22 years, their average length of driving experience is 4.14 years, and the average time in which drivers have worked in Ningbo is 7.35 years. More details are shown in Table 2.

\section{Methods}

This study was aimed at the relationships among acceptance of parking App, trust in parking App, perceived usefulness, and other related variables. The latent variables
TABLE 2: Characteristics of respondents.

\begin{tabular}{lcc}
\hline Variable & \multicolumn{2}{c}{ Category } \\
\hline & $<20$ & 5.7 \\
Age & $20-30$ & 58.0 \\
& $30-40$ & 17.6 \\
& $40-50$ & 15.4 \\
\multirow{2}{*}{ Gender } & $>50$ & 3.3 \\
\hline \multirow{3}{*}{ Driving years } & Male & 57 \\
& Female & 43 \\
\hline \multirow{2}{*}{ How long have you worked in the } & $<5$ & 66.7 \\
city? (years) & $5-10$ & 19 \\
& $>10$ & 14.3 \\
\multirow{2}{*}{ Education } & $<5$ & 68.6 \\
& $>10$ & 15 \\
& Higher (college or & 72 \\
\hline
\end{tabular}

and observable variables were shown in Table 1. SEM (the structural equation model) methodology [28] can simultaneously analyze and capture the complex interrelationships among the intention of drivers to use parking App, perceived usefulness, perceived ease of use, and sociodemographic and other related variables. The effects of observed and latent variables can be decomposed into direct and indirect effects in this model. SEM also allows a user to have standardized parameters that show the relative influences of observed and latent variables with a lower error. Considering the complex relationships among these variables and their measurement error, SEM was applied as the best option.

AMOS software is easy to model without programming and includes almost all the frontier statistical methods related to structural equation model. In all 
structural equation regression analysis software, including AMOS, LISREL, and MPLUS, the drawing interface of AMOS is the most clear and comfortable and is convenient to check errors and correct models. Because Amos is relatively simple, old software, nonstatistical researchers can also use it to study. Therefore, this paper selected the latest version of AMOS 21.0 for structural equation model analysis. Figure 3 shows the relationship among the variables. In SEM, the underlying theory of the phenomena under investigation plays a key role in assessing model adequacy and testing relationships among the variables. The model contains two endogenous latent variables: the intention of drivers to accept parking App and perceived usefulness. A set of 4 independent exogenous variables was identified. These variables are sociodemographics, parking App attributes, trust in parking App, and perceived ease of use that might influence the intention to accept the parking App. Besides, SD1 SD6 are the six measurement variables of sociodemographics; PAA1 PAA6 are the six measurement variables of parking App attributes; PU1 PU2 are the two measurement variables of perceived usefulness; TPA1 TPA2 are the two measurement variables of trust in parking App; PEOU1 PEOU2 are the two measurement variables of perceived ease of use; IUPA1 is the measurement variable of the intention to use the parking App.

In addition, e1 e19 were the errors of each observable variable. Since parking App attributes and perceived usefulness affect each other, double arrows were used to represent the relationships between them.

\section{Goodness of Fit and Estimated Results}

This model obtains the initial parameter estimates by running AMOS 21.0. According to the output fitting index results and connecting the theory, the model is constantly modified. Finally, the running results of the model with good fitting degree are obtained, which meet the standard requirements. Figure 4 shows the path diagrams.

The indices for goodness of fit are summarized in Table 3. The comparison of the absolute fix index with accepted criteria shows that $\chi^{2}$ /degrees of freedom, goodness-of-fit index, and root-mean-square error of approximation all meet the requirements. Other indices, such as incremental fit index, 0.920, and comparative fit index, 0.919, are higher than the accepted criterion of 0.9 . All these indices indicate that the explanatory power of the model is high.

6.1. Hypothesis Testing. The overall fit indices show that the final model fits the data very well and is accepted. Hence, the hypothesis relationships in the conceptual framework can be tested through the standardized path coefficients between latent variables. The testing results for the six assumed relationships are summarized in Table 4.

Four of the six hypotheses in the conceptual framework are significantly supported. In addition, a new relationship between parking App attributes and perceived usefulness is discovered. The supported $H_{1}$ indicates that drivers' perceived usefulness $\left(\beta_{1}=0.984, P_{1}=0.046\right)$ positively and significantly influences intention to accept parking App. $\mathrm{H}_{2}$ is also supported in the results, which indicates that drivers' perceived ease of use $\left(\beta_{2}=-0.079, P_{2}=0.017\right)$ positively and significantly influences the perceived usefulness of parking App. The supported $\mathrm{H}_{3}$ indicates that drivers' perceived ease of use $\left(\beta_{3}=-0.306, P_{3}<0.001\right)$ positively and significantly influences intention to accept parking App. $H_{5}$ is significant, which indicates that drivers' trust in App $\left(\beta_{5}=0.381\right.$, $\left.P_{5}<0.001\right)$ positively and significantly influences intention to accept parking App.

It is worth mentioning that the influence coefficient of perceived ease of use on perceived usefulness and drivers' intention is negative, which is due to the negative correlation between the latent variable and its observation variables in Table 1 . When analyzing the results, the negative sign should be removed; that is, perceived ease of use positively and significantly affects perceived usefulness and intention to accept parking App.

Although sociodemographics of drivers do not have significant relationship with drivers' intention to accept parking App, we can also draw some conclusions from Figure 4. The observed indicator variables of age, driving ages, and how long respondents have worked in the city show a negative relationship with acceptance intention. It indicates that with the growth of age and driving experience, and the increase of working time in the local area, the drivers will become more familiar with the local parking conditions and will use parking App less but by virtue of experience. Furthermore, gender appears to have a negative relationship with acceptance intention, which means that women are more likely to accept parking App, and this assuredly provides a new direction for the publicity of parking App.

6.2. Analysis of Direct, Indirect, and Total Effects. The direct effects and total effects between latent variables can be used to analyze the strength of each causal relationship. A direct effect is the influence of one variable on another that is not mediated by any other variables, and an indirect effect is one that is mediated by at least one other variable. The total effect of one variable on another is the sum of the direct and indirect effects. The path coefficients shown in the previous subsection are all direct effects. Since an indirect relationship might exist between latent variables, it is often useful to calculate the direct and indirect effects from the model to get a better understanding of the model estimation results.

Direct, indirect, and total effects between latent variables are given in Table 5. They can be used to analyze the different weights of factors on acceptance intention. From Table 5, it can be seen that in four factors that are significantly related to acceptance intention, perceived usefulness has the largest total effect by a coefficient of 0.984 , followed by parking App attributes and perceived ease of use, which have a total effect on acceptance intention by coefficients of 0.743 and 0.384 , respectively. Trust in parking App has the least total effect on acceptance intention by a coefficient of 0.381 . It can also be seen that among the four determinants of acceptance 


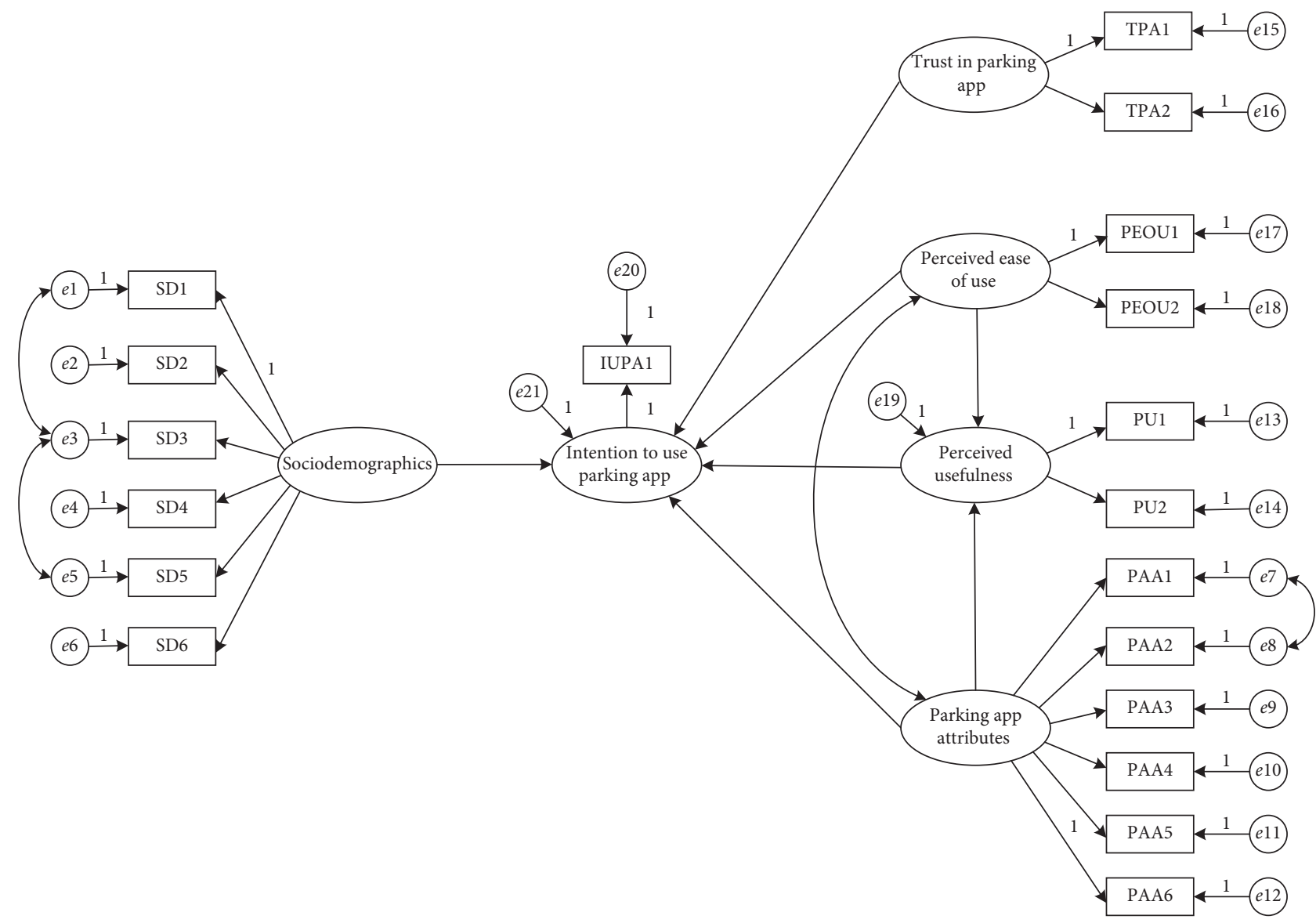

Figure 3: SEM of drivers' intention to accept parking App.

intention, there is no indirect relationship between trust in parking App and acceptance intention or between perceived usefulness and acceptance intention.

Furthermore, the total effects are significant and large between perceived ease of use and perceived usefulness and between parking App attributes and perceived usefulness; they are 0.079 and 0.947 , respectively. So parking App attributes have a great impact on perceived usefulness. The influence of perceived usefulness on acceptance intention largely comes from the parking App attributes. That is to say, although the parking App attributes do not directly affect the acceptance intention, they do that indirectly through the influence of perceived usefulness.

\section{Discussion of Results}

From hypothesis test and coefficient analysis, the following can be found.

The significant relationships among drivers' intention to accept parking App:

(1) Perceived usefulness has the greatest influence on the parking App acceptance intention. It can be seen that perceived usefulness of parking App plays a key role in the acceptance intention. Due to more vehicles but less parking spaces in China, it is difficult for drivers to quickly find parking lots by themselves. The biggest responsibility of parking App is to provide drivers with parking information and simplify their parking search process. And the biggest problem with most parking Apps is data collection of actual parking spaces. If the information transmitted by the App is wrong and the information updates lag, the App will not bring convenience to the users but mislead the users or bring unnecessary troubles to the drivers. Therefore, information data collection is the focus of most parking App at present, and it is also the inevitable development trend of this market. Future research is needed to solve the problem of how to strengthen cooperation between App operators and parking suppliers.

(2) Perceived ease of use has the second largest effect on parking App acceptance intention, and this effect is significant at 0.001 level. It has a lot to do with parking problems in China. Because of the limitation of parking permits, the parking information received by the parking users is various. If users cannot get useful information quickly, they will think that the parking App is not convenient for them to park and give up using the App. On one hand, the App should control the amount of advertising; on the other hand, it should strengthen information management to avoid unnecessary 


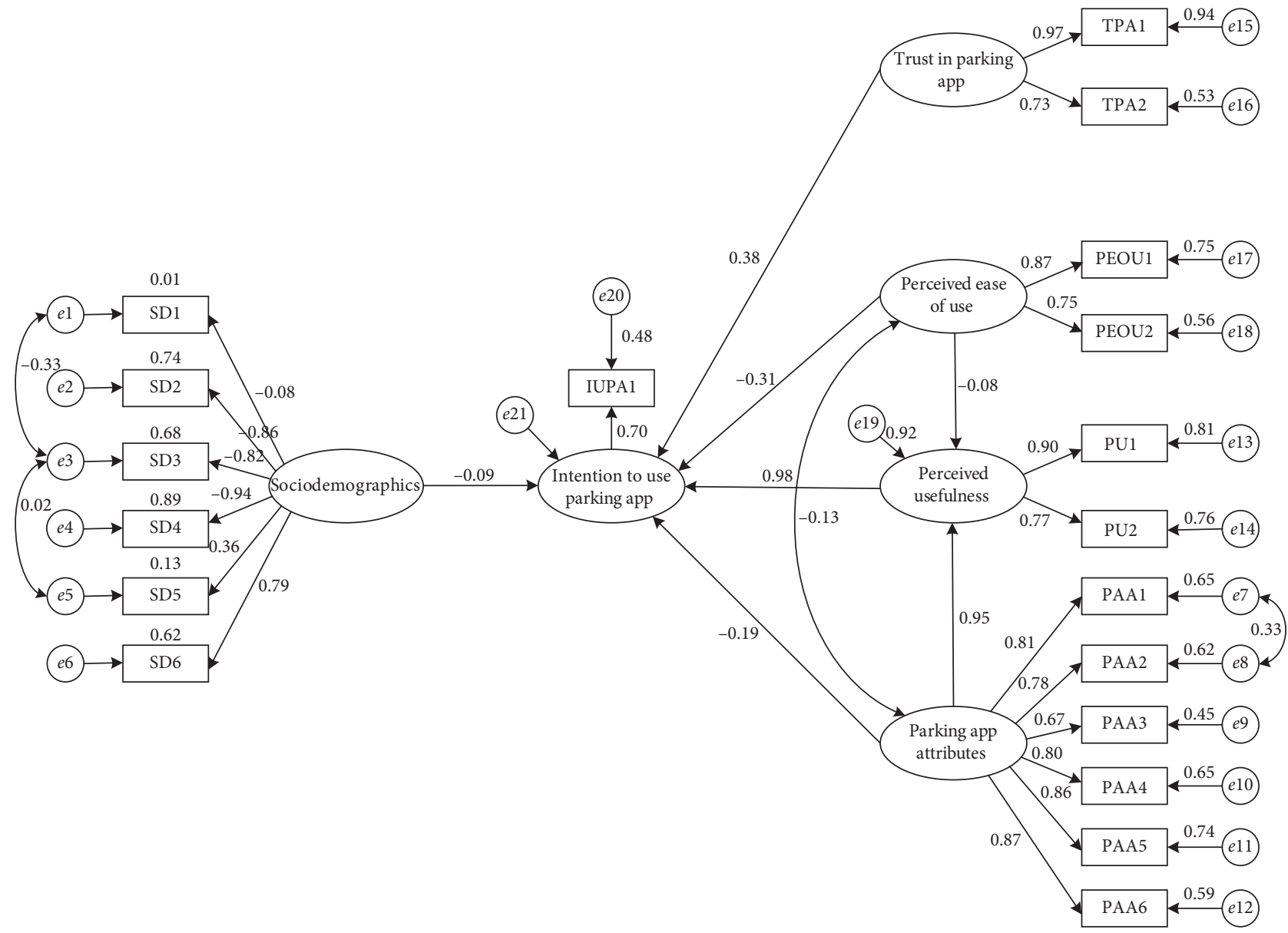

FIgURE 4: Measurement and structural model with standardized estimates.

TABLe 3: Overall fit indices for model.

\begin{tabular}{lcc}
\hline Index & Value of indices in model & Criteria value \\
\hline$\chi^{2} / \mathrm{DF}$ & 3.380 & $<5.0$ \\
GFI & 0.905 & $>0.9$ \\
NFI & 0.890 & $>0.8$ \\
IFI & 0.920 & $>0.9$ \\
CFI & 0.919 & $>0.9$ \\
RMSEA & 0.075 & $<0.1$ \\
\hline
\end{tabular}

$\mathrm{DF}=$ degrees of freedom, GFI $=$ goodness-of-fit index, NFI $=$ normed fit index, IFI = incremental fit index, $\mathrm{CFI}=$ comparative fit index, RMSEA = root-mean-square error of approximation.

information interfering with users. Meanwhile, parking App need to develop more functions to enhance users' convenience. For example, parking App can be connected with the parking lock to realize intelligent remote control, which is convenient for drivers to manage parking spaces and prevent their parking spaces from being occupied by others.

(3) Trust in parking App has a great influence on parking App acceptance intention. Obviously, if the parking information provided by App is not accurate enough or could not change in real time according to the actual situation, drivers will naturally reduce the confidence of parking information, think that parking information is not important, believe more in their own judgement, and reduce the use of parking App.

The ways to increase the intention of drivers to use parking App:

In the sociodemographic variables, the observed indicator variables of gender appear to have a positive relationship with acceptance intention, and age appears to have a negative relationship with acceptance intention, which means that compared with men and old people, women and young people are more likely to accept parking App. So it is suggested that parking App should increase publicity for female and young drivers. In addition, education shows a positive relationship with acceptance intention, so one suggestion is that parking App should be promoted to people with higher education.

The ultimate goal of parking App is able to obtain accurate parking data, parking reservation, and fast online payment, which can change the traditional passive parking mode of "first arrive, then park." There are many functions waiting to be developed. Firstly, the function of internal guidance and parked vehicles track inside parking area should be opened, 
TABLE 4: Hypothesis testing results.

\begin{tabular}{lcccc}
\hline Hypothesis & Model path & Coefficients between two variables & $P$ value & Test result \\
\hline$H_{1}$ & Perceived usefulness $\longrightarrow$ intention to use parking App & $\beta 1=0.984$ & $P_{1}=0.046$ & Significant \\
$H_{2}$ & Perceived ease of use $\longrightarrow$ perceived usefulness & $\beta 2=-0.079$ & $P_{2}=0.017$ & Significant \\
$H_{3}$ & Perceived ease of use $\longrightarrow$ intention to use parking App & $\beta 3=-0.306$ & $P_{3}\left({ }^{* * *}\right)$ & Significant \\
$H_{4}$ & Parking App attributes $\longrightarrow$ intention to use parking App & $\beta 4=-0.189$ & $P_{4}=0.690$ Not significant \\
$H_{5}$ & Trust in parking App $\longrightarrow$ intention to use parking App & $\beta 5=0.381$ & $P_{5}(* * *)$ & Significant \\
$H_{6}$ & Sociodemographics $\longrightarrow$ intention to use parking App & $\beta 6=-0.087$ & $P_{6}=0.240$ Not significant \\
\hline
\end{tabular}

TABLE 5: Direct, indirect, and total effects between latent variables.

\begin{tabular}{|c|c|c|c|}
\hline Relation between latent variables & Direct effects & Indirect effects & Total effects \\
\hline Perceived usefulness $\longrightarrow$ intention to use parking App & $0.984^{*}$ & -- & $0.984^{*}$ \\
\hline Perceived ease of use $\longrightarrow$ intention to use parking App & $0.306^{* * *}$ & $0.078^{*}$ & $0.384^{* * *}$ \\
\hline Parking App attributes $\longrightarrow$ intention to use parking App & -0.189 & $0.932^{* * *}$ & 0.743 \\
\hline Trust in parking App $\longrightarrow$ intention to use parking App & $0.381^{* * *}$ & -1 & $0.381^{* * *}$ \\
\hline Sociodemographics $\longrightarrow$ intention to use parking App & -0.087 & - - & -0.087 \\
\hline Perceived ease of use $\longrightarrow$ perceived usefulness & $0.079^{*}$ & - & $0.079^{*}$ \\
\hline Parking App attributes $\longrightarrow$ perceived usefulness & $0.947^{* * *}$ & -- & $0.947^{* * *}$ \\
\hline
\end{tabular}

${ }^{*} p<0.1 ;{ }^{* *} p<0.01 ;{ }^{* * *} p<0.001$.

so that it will be easier for drivers to enter the parking lot and find their car when they leave. Then, it needs to add a hire driving function to provide the driving agent service for car owners, so as to avoid being unable to drive when they pick up the car from the parking lot because of drinking alcohol. Moreover, it can also add a traffic violation inquiry function to help car owners timely learn about the violation so as to deal with it.

\section{Conclusions}

The purpose of this study is to develop and validate the hypothesis that perceived usefulness, perceived ease of use, and other latent variables are determinants of using parking App. Most previous work studied smart parking system through modeling the functional design of parking App or evaluating the performance of parking App. Unlike the existing literature, the model in this study, from a psychometric perspective, is intended to confirm that the measurement scales of perceived usefulness, perceived ease of use, and other latent variables have significant empirical relationships with measurement scales of parking App acceptance intention.

To summarize the results, four main insights concerning the determinants of parking App acceptance were found:

(i) Perceived usefulness is a major determinant of parking App acceptance intention

(ii) Parking App attributes is a significant secondary determinant of parking App acceptance intention, and it indirectly determines drivers' acceptance intention by influencing perceived usefulness

(iii) Perceived ease of use is a third important determinant of parking App acceptance intention (iv) Trust in parking App is a significant determinant of parking App acceptance intention

These findings have implications for increasing drivers' acceptance intention of parking App and improving the service quality of parking App in China.

Since perceived usefulness has the greatest impact on parking App acceptance intention, parking App should improve the accuracy of information release, speed up information updating, and avoid unnecessary information to produce adverse effects on users. The important factor affecting perceived usefulness is parking App attributes. Therefore, parking App operators should not only ensure accurate information but also open parking reservation, internal guidance, and parked vehicles track, electronic payment functions as soon as possible to enhance the attractiveness of users. Only by developing more functions can the perceived usefulness of users and the acceptance of parking App be improved.

Perceived ease of use is an important factor affecting parking App acceptance intention. How to make parking App more acceptable to users is a problem that operators need to consider. Improving the clarity and simplicity of information provided by parking App can enhance the perception and usability of App to users. In order to improve users' perceived ease of use, parking App can develop hire driving service, violation inquiry function, and provide longterm rental for car owners to facilitate their use.

Finally, trust in parking App puts forward higher requirements for the accuracy and real time of parking information. This means that operators need to work with information suppliers to ensure reliable access to information such as parking spaces and parking price. Undoubtedly, increasing the trust in parking App can increase the driver's use of parking App. At the same time, parking App can add sharing functions with WeChat, QQ, and other 
platforms to upload synchronously, which can improve user stickiness and strengthen their trust in parking App.

This is the first article to study the impact of intelligent parking App on drivers' parking behavior, which has great guiding significance for parking research at home and abroad. The methods in this paper also provide a new way to solve the parking problem under the background of intelligence. Based on the establishment and analysis of model, we can understand the user behavior mechanism and put forward the parking App promotion strategy. In terms of reducing urban congestion and environmental pollution, this paper is of some theoretical and practical value. It is worth noting that due to the differences in population, parking types, and modes, the conclusions of this paper are helpful for the release of parking information in China, but the guiding significance for other countries needs additional investigation and research.

\section{Data Availability}

The data used to support the findings of this study are available from the corresponding author upon request.

\section{Conflicts of Interest}

The authors declare that they have no conflicts of interest.

\section{Acknowledgments}

This research was supported by the projects of the Natural Science Foundation of Zhejiang Province, China (LY20E080011), National Natural Science Foundation of China (no. 71971059), National Key Research and Development Program of China-Traffic Modeling, Surveillance and Control with Connected and Automated Vehicles (2017YFE9134700), and National Natural Science Foundation of China (no. 71701108 and 71861006). The authors thank their mentor, Xiaofei Ye of the Ningbo University, who gave instruction on writing this paper. The authors also thank the interviewers for their assistance in the survey.

\section{References}

[1] C. G. Chorus, E. J. E. Molin, and B. Van Wee, "Use and effects of advanced traveler information services (ATIS): a review of the literature," Transport Reviews, vol. 26, pp. 127-149, 2006.

[2] C. G. Chorus, E. J. E. Molin, B. Van Wee, T. A. Arentze, and H. J. P. Timmermans, "Responses to transit information among car-drivers: regret-based models and simulations," Transportation Planning and Technology, vol. 29, no. 4, pp. 249-271, 2006.

[3] K. Dziekan and K. Kottenhoff, "Dynamic at-stop real-time information displays for public transport: effects on customers," Transportation Research Part A: Policy and Practice, vol. 41, no. 6, pp. 489-501, 2006.

[4] C. Brakewood, S. Barbeau, and K. Watkins, "An experiment evaluating the impacts of real-time transit information on bus riders in Tampa, Florida," Transportation Research Part A: Policy and Practice, vol. 69, pp. 409-422, 2014.

[5] K. G. Goulias, T.-G. Kim, and O. Pribyl, "A longitudinal analysis of awareness and use for advanced traveler information systems," Journal of Intelligent Transportation Systems, vol. 8, no. 1, pp. 3-17, 2004.

[6] E. J. E. Molin and H. J. P. Timmermans, "Traveler expectations and willingness-to-pay for web-enabled public transport information services," Transportation Research Part C: Emerging Technologies, vol. 14, no. 2, pp. 57-67, 2006.

[7] J.-W. Grotenhuis, B. W. Wiegmans, and P. Rietveld, “The desired quality of integrated multimodal travel information in public transport: customer needs for time and effort savings," Transport Policy, vol. 14, no. 1, pp. 27-38, 2006.

[8] S. Farag and G. Lyons, "What affects use of pre-trip public transport information? Empirical results of a qualitative study," Transportation Research Record, pp. 85-92, Transportation Research Board, Washington, DC, USA, 2008.

[9] S. Farag and G. Lyons, "To use or not to use? An empirical study of pre-trip public transport information for business and leisure trips and comparison with car travel," Transport Policy, vol. 20, pp. 82-92, 2012.

[10] Z. Liu, An Analysis of Technology Acceptance Model: Exploring User Acceptance and Intention of Taxi-Hailing App in Shanghai, University of Gothenburg, Gothenburg, Sweden, 2014.

[11] L. Peng, H. Wang, and X. He, "Exploring factors affecting the user adoption of call-taxi app," in Proceedings of the 25th Australasian Conference on Information System, Auckland, New Zealand, 2014.

[12] Y. Zhang, H. Guo, C. Li, W. Wang, X. Jiang, and Y. Liu, "Which one is more attractive to traveler, taxi or tailored taxi? An empirical study in China," Procedia Engineering, vol. 137, pp. 867-875, 2016.

[13] Z. Tang, Design and Implementation of Intelligent Parking Guidance System, Southwest Jiaotong University, Chengdu, China, 2017.

[14] C. Song, The Design and Implementation of Phone Parking APP System, Jilin University, Changchun, China, 2016.

[15] M. Hancer and Y. I. Jin, "Shaping travelers' attitude toward travel mobile applications," Journal of Hospitality \& Tourism Technology, vol. 5, no. 2, pp. 177-193, 2014.

[16] J. M. Kwon, J. I. Bae, and S. C. Blum, "Mobile applications in the hospitality industry," Journal of Hospitality \& Tourism Technology, vol. 4, no. 1, pp. 81-92, 2013.

[17] S. Jamal and M. A. Habib, "Smartphone and daily travel: how the use of smartphone applications affect travel decisions," Sustainable Cities and Society, vol. 53, Article ID 101939, 2020.

[18] Y. Xie, M. Danaf, C. Lima Azevedo et al., "Behavioral modeling of on-demand mobility services: general framework and application to sustainable travel incentives," Transportation, vol. 46, no. 6, pp. 2017-2039, 2019.

[19] M. Fishbein and B. Ajzen, Attitude, Intention, and Behavior: An Introduction to Theory and Research, Addition-Wesly, Boston, MA, USA, 1975.

[20] F. D. Davis, "Perceived usefulness, perceived ease of use, and user acceptance of information technology," MIS Quarterly, vol. 13, pp. 318-339, 1989.

[21] A. Nadia, S. M. Nordin, and M. A. Bahruddin, "How trust can drive forward the user acceptance to the technology? In-vehicle technology for autonomous vehicle," Transportation Research Part A: Policy and Practice, vol. 97, p. 118, 2018.

[22] F. D. Davis, R. P. Bagozzi, and P. R. Warshaw, "User acceptance of computer technology: a comparison of two theoretical models," Management Science, vol. 35, no. 8, pp. 982-1003, 1989. 
[23] V. Venkatesh and F. D. Davis, "A theoretical extension of the technology acceptance model: four longitudinal field studies," Management Science, vol. 46, no. 2, pp. 186-204, 2000.

[24] E. Daniels, M. Levin, and J. McDermott, "Improving commercial radio traffic reports in the Chicago area," Transportation Research Record 600, pp. 52-57, Transportation Research Board, Washington, DC, USA, 1976.

[25] A. J. Khattak, J. L. Schofer, and F. S. Koppelman, "Effect of traffic reports on commuters' route and departure time changes," in Proceedings of the Vehicle Navigation and Information Systems Conference, vol. 2, pp. 669-679, IEEE, Dearborn, MI, USA, 1991.

[26] F. L. Mannering, "Poisson analysis of commuter flexibility in changing routes and departure times," Transportation Research Part B: Methodological, vol. 23, no. 1, pp. 53-60, 1989.

[27] Y. Geng and C. G. Cassandras, "New "smart parking" system based on resource allocation and reservations," IEEE Transactions on Intelligent Transportation Systems, vol. 14, no. 3, pp. 1129-1139, 2013.

[28] J.-H. Wu, Y.-C. Chen, and Li-M. Lin, "Empirical evaluation of the revised end user computing acceptance model," Computers in Human Behavior, vol. 23, no. 1, pp. 162-174, 2007. 